\title{
Capability of Regional Climate Models in Simulating Coastal Winds and Waves around Japan
}

\author{
Wataru SASAKI \\ Application Laboratory, Japan Agency for Marine-Earth Science and Technology, Yokohama, Japan
}

Satoshi IIZUKA

Storm, Flood, and Landslide Research Department, National Research Institute for Earth Science and Disaster Prevention, Tsukuba, Japan

and

Koji DAIRAKU

Social System Research Department, National Research Institute for Earth Science and Disaster Prevention, Tsukuba, Japan

(Manuscript received 5 July 2011, in final form 13 July 2012)

\begin{abstract}
We assessed the capability of the regional climate model (RCM) approach in simulating the monthly 50th and 99th percentiles of marine wind speed and significant wave height on the Japanese coast during tropical cyclone season (June-October) of 2002-2004. To simulate the marine winds, we performed dynamical downscaling of the Japanese Reanalysis (JRA-25) using three RCMs. We found that, by applying the Brier skill score, coastal wind speed of the RCMs is closer to the observed, when compared to the JRA-25. The better performance of the RCM approach was found to come from a successful reduction of the bias rather than that of the root mean square error. The RCMs, however, simulate erroneously low (high) marine wind speed northeast of Japan (along the Pacific coast and Kuroshio Extension). The erroneous marine wind speed was found to be related with the sea surface temperature bias associated with the coarse horizontal resolution of the JRA-25. We employed the dynamically-downscaled marine winds to force a wave model (WaveWATCH-III), and found that the marine winds of the RCMs are more effective than the JRA-25 in reproducing significant wave height on the Japan Sea coast.
\end{abstract}

\section{Introduction}

Coastal waves are one of the main climate drivers for coastal systems (IPCC AR4 WG-II, 2007). There have been a number of assessments of high waves and storm surges in the North Sea on warming climate

Corresponding author: Wataru Sasaki, Application Laboratory, Japan Agency for Marine-Earth Science and Technology, 3173-25 Showa-machi, Kanazawa-ku, Yokohama, Kanagawa 236-0001, Japan.

E-mail: wsasaki@jamstec.go.jp

(C)2012, Meteorological Society of Japan conditions since the pioneer study of the WASA project (von Storch 1998; refer to Weisse et al. 2009 for further references). One of the main drivers for ocean surface waves is marine winds. Therefore accurate estimates for marine winds are indispensable for the accurate estimates of ocean surface waves. Coastal areas of East Asia, including Japan, suffers from winds induced by tropical cyclones (TC) and the monsoon. Previous studies suggest that TC-induced societal damages are sensitive to TC wind speed (Pielke 2007; Nordhaus 2006). However, it is difficult for current coupled general circulation models (CGCMs), which 
(a) RAMS

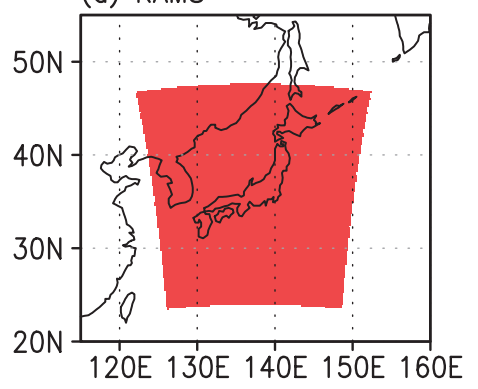

(b) $\mathrm{NHM}$

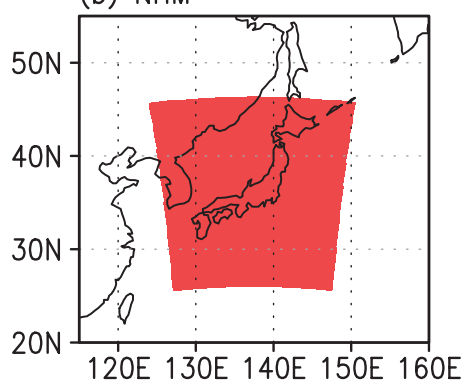

(c) WRF

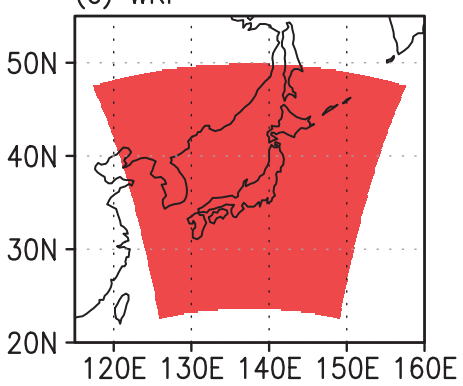

Fig. 1. Model domain for (a) RAMS, (b) NHM, and (c) WRF.

are commonly used for global warming projections, to simulate surface winds associated with TCs since the horizontal resolution of the CGCMs cannot resolve TC structure and associated extreme events. One of the powerful approaches to avoid the limitation of the CGCMs is a dynamical downscaling approach with the use of regional climate models (RCMs). Application of the RCMs span both past and possible future climates, facilitating climate impact studies, information and support to climate policy, and adaptation (Rummukainen 2010). Although the RCM approach is indeed a useful and powerful technique, there are uncertainties due to differences in the physical schemes and numerical techniques in different RCMs, even though the same initial and/or boundary conditions are applied. It is therefore important to gain the basic knowledge about the characteristics and validity of RCMs.

In this study, we investigate whether the RCM approach retains or adds value to simulate coastal wind speed around Japan during TC seasons (June-October). In addition, we examine the capability of marine winds of the RCMs in simulating coastal wave height around Japan.

The rest of this paper is structured as follows: Section 2 describes the models, datasets, and experimental design; Results are presented in Section 3; and Section 4 provides summary and discussion.

\section{Model, data and experimental design}

\subsection{Regional climate model}

We employ three non-hydrostatic RCMs; modified RAMS (Dairaku 2008), which originally comes from the Regional Atmospheric Modeling System (Liston and Pielke 2000), Non-Hydrostatic Model (NHM; Saito 2007), and Weather Research and Forecast (WRF; Skamarock et al. 2007). These RCMs are configured at a spacing of $20-\mathrm{km}$ latitude-longitude mesh covering the Japanese archipelago, although the domain size varies from one model to another (Fig. 1). The numbers of vertical levels are different among the RCMs (27 for RAMS, 40 for NHM, and 31 for WRF). The lateral and lower boundaries are updated every 6-hour based on the 25-yr Japanese Reanalysis (JRA25; Onogi et al. 2007). The JRA-25 assimilates not only the conventional observations, but also atmospheric motion vector wind retrieved from geostationary satellites, brightness temperature from TOVS and ATOVS, precipitable water retrieved from SSM/I radiance, and wind profile retrievals surrounding TCs. The global model used for the JRA-25 has a spectral resolution of T106 and 40 vertical layers with the top at $0.4 \mathrm{hPa}$. The lateral and lower boundary conditions for the RCMs are spatially interpolated from the reanalysis grid to that of the RCMs. We employ a cumulus convection scheme proposed by Kain and Fritsch (1993) for the RAMS and WRF, while the modified version of the Kain and Fritsch scheme (Ohmori and Yamada 2004; Narita and Ohmori 2007) is used for the NHM. Observed data are not assimilated into the RCMs. The RCMs are integrated for 3 years during 2002-2004.

In this study we focus on the monthly $50^{\text {th }}$ and $99^{\text {th }}$ percentile of marine wind speed $\left(\mathrm{W}_{50}\right.$ and $\left.\mathrm{W}_{99}\right)$ during a TC season for Japan (from June to October). The monthly $50^{\text {th }}$ and $99^{\text {th }}$ percentiles of the marine wind speed of the RCMs are calculated from the model outputs at 1-hour intervals, while those of the JRA25 are calculated from the original JRA-25 at 6-hour intervals. To compare among the datasets, all modeled wind fields are gridded by $0.1^{\circ} \times 0.1^{\circ}$ through the approximately quadratic interpolation method.

\subsection{Wave model}

Ocean wave fields are simulated by the WAVEWATCH III (Tolman 2002), which is a fullspectral third-generation wave model developed at the 
(a) $W_{\text {so, }}$ BSW

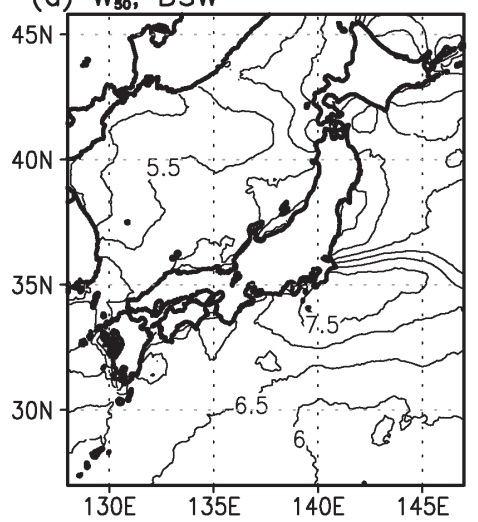

(c) $\triangle W_{\text {so }}$ (JRA25 minus BSW)

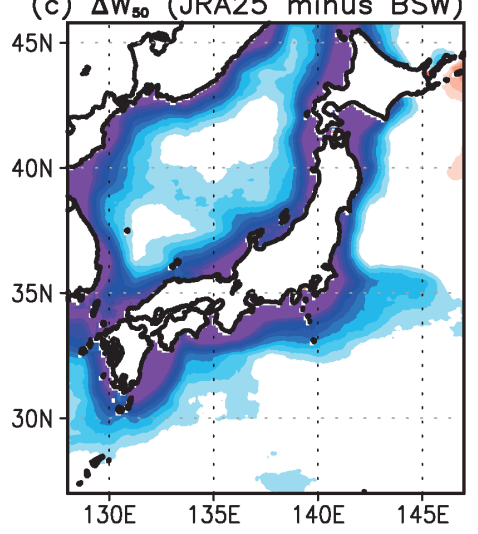

(e) $\triangle W_{\text {so, }}, \mathrm{RMSE}$

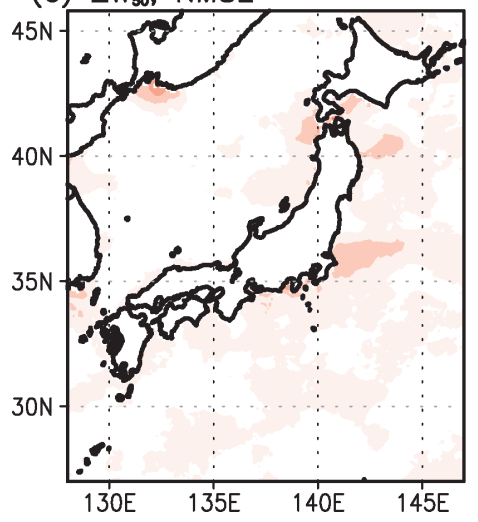

(b) $\mathrm{W}_{99}, \mathrm{BSW}$

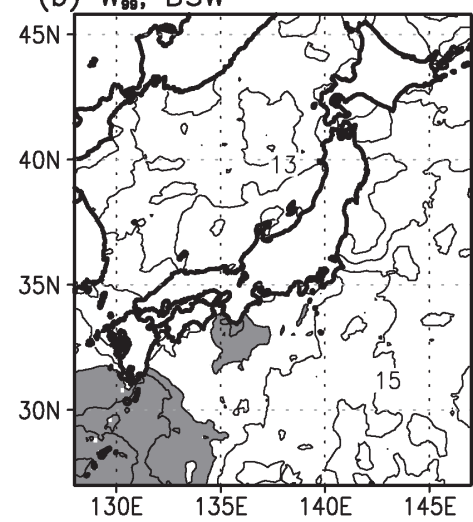

(d) $\Delta W_{9}$ (JRA25 minus BSW)

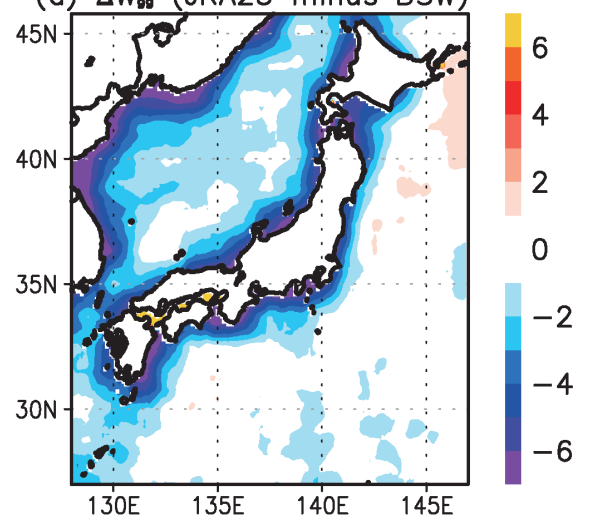

(f) $\Delta W_{99}, R M S E$

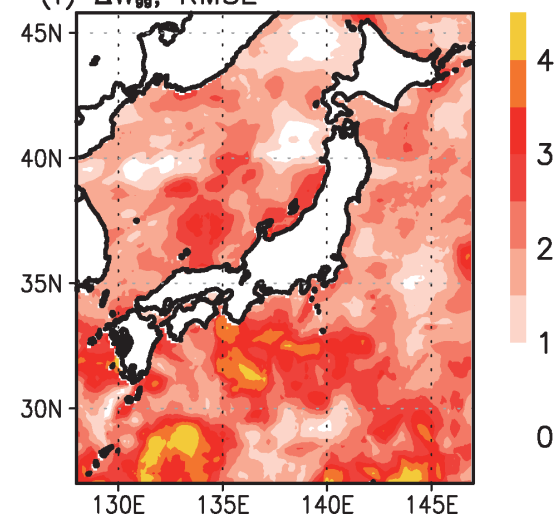

Fig. 2. (a) and (b) show $\mathrm{W}_{50}$ and $\mathrm{W}_{99}$ averaged for June-October of 2002-2004, respectively. The shading shows the marine wind speed exceeding $17 \mathrm{~ms}^{-1}$. (c) and (d) display the bias of $\mathrm{W}_{50}$ and $\mathrm{W}_{99}$ for JRA-25 relative to BSW, respectively. (e) and (f) depict the root mean square error of $\mathrm{W}_{50}$ and $\mathrm{W}_{99}$ of JRA-25 relative to BSW. Unit is $\mathrm{ms}^{-1}$.

National Oceanic and Atmospheric AdministrationNational Centers for Environmental Prediction. We prepared two models; a parent model and child one. Wave spectra simulated by the parent model are used as the lateral boundary condition for the child model. The parent model is configured at $1.125^{\circ}$ latitude-longitude mesh spacing covering the western North Pacific $\left(0^{\circ}-\right.$ $\left.60^{\circ} \mathrm{N}, 120^{\circ} \mathrm{E}-180^{\circ}\right)$. Although the model domain for the parent model has closed boundaries in the Pacific, the swells formed outside of the computational domain would not unduly change the variation of significant wave height on the Japanese coast. The parent model 

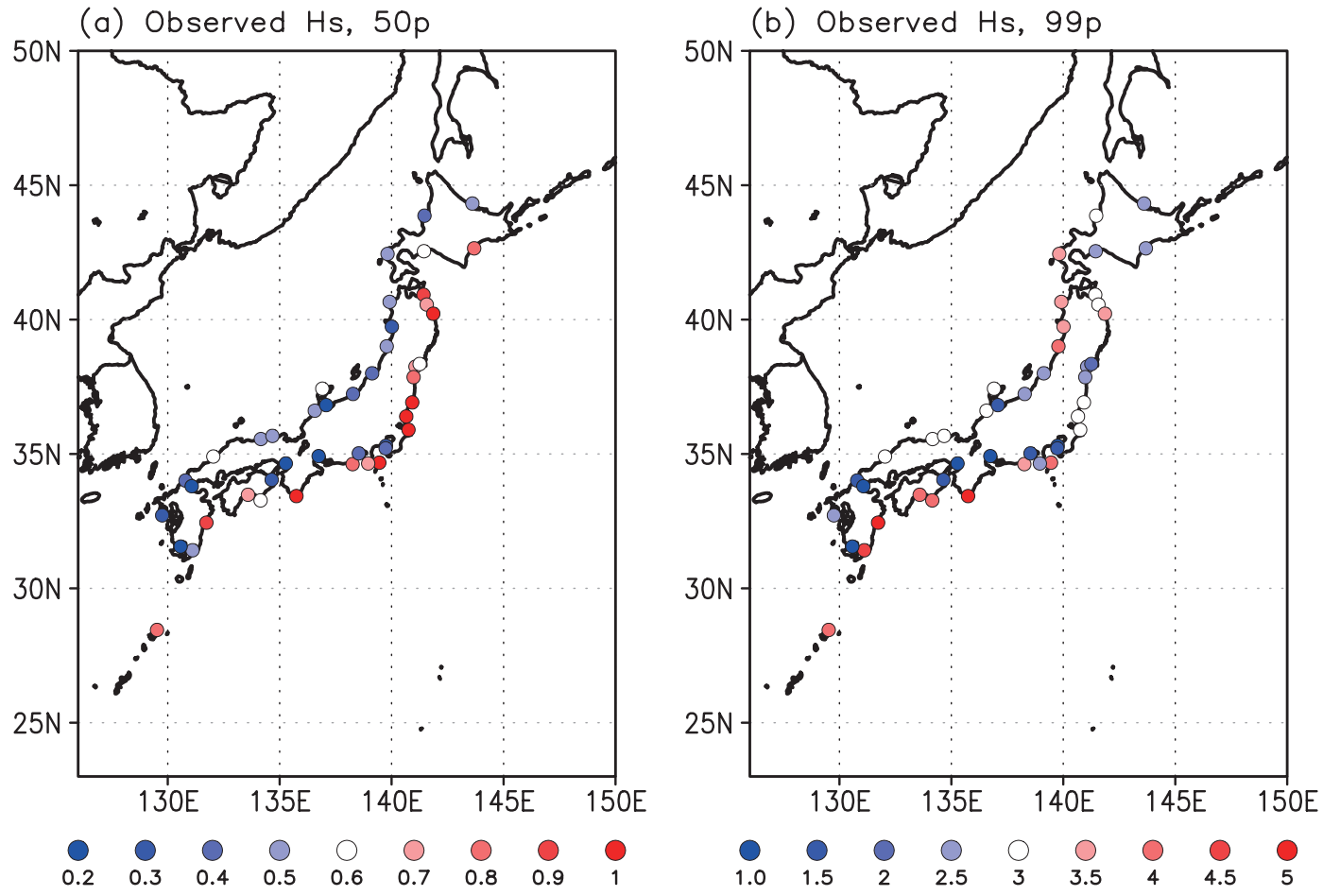

Fig. 3. Observed (a) $\mathrm{H}_{50}$ and (b) $\mathrm{H}_{99}$ averaged for June-October of 2002-2004. Unit is m.

is forced by marine wind fields of the JRA-25. The child model is configured at $0.1^{\circ}$ latitude-longitude mesh spacing covering the Japanese archipelago $\left(27^{\circ} \mathrm{N}-48^{\circ} \mathrm{N}, 126^{\circ} \mathrm{E}-147^{\circ} \mathrm{E}\right)$. For both of the parent and child models, the wave spectrum is resolved into 24 directions and 23 frequencies. The directions begin at $0^{\circ}$ and span $360^{\circ}$ clockwise in $15^{\circ}$ increments. The frequencies begin with the lowest frequency at $0.04118 \mathrm{~Hz}$ and are logarithmically spaced with an increment factor of 1.1. The child model is driven by marine winds simulated by the RCMs and the JRA25 . The monthly $50^{\text {th }}$ and $99^{\text {th }}$ percentiles of significant wave height $\left(\mathrm{H}_{50}\right.$ and $\left.\mathrm{H}_{99}\right)$ from June to October are calculated from the outputs at 1-hour intervals.

\subsection{Data}

a. Observed marine wind speed and significant wave height

To validate the modeled marine surface wind speed, we use Blended Sea Winds (BSWs; Zhang et al. 2006) which are generated by blending surface wind speed measured by multiple (up to six) satellites. The BSWs are globally gridded on a $0.25^{\circ} \times 0.25^{\circ}$ horizontal resolution, and a time resolution of 6-hour. We use the BSWs from 00Z01Jun2002 to 18Z31Oct2004.
At 6-hour temporal resolution, the spatial coverage between $65^{\circ} \mathrm{S}-65^{\circ} \mathrm{N}$ for the wind speed data of the BSW exceeds $90 \%$ after June 2002, thanks to the use of AMSR-E (Zhang et al. 2006). We, however, note that there is a lack of high winds measurements associated with TCs. Therefore the robustness of the $99^{\text {th }}$ percentile wind speed for the BSW is less than that of the JRA-25. In contrast, the $99^{\text {th }}$ percentile wind speed for the RCMs is more robust than the BSW and JRA-25, since the former is made of the hourly wind speed data. In order to compare with modeled marine winds, the BSWs are interpolated into a $0.1^{\circ} \times 0.1^{\circ}$ grid by applying the approximately quadratic interpolation. Figures $2 \mathrm{a}$ and $\mathrm{b}$ show the climatological JuneOctober mean of $\mathrm{W}_{50}$ and $\mathrm{W}_{99}$ of the BSWs. The BSW effectively captures high wind speed exceeding 17 $\mathrm{ms}^{-1}$ south of Japan during TC season (Fig. 2b).

Modeled significant wave heights are compared against in-situ wave data measured by the Nationwide Ocean Wave information network for Ports and HAbourS (NOWPHAS). The NOWPHAS archives wave parameters at coastal observation points in Japan every 2 -hours. We select 75 observation points in which observed data are available during 20022004. We exclude observation points which are not 
(a) RAMS 50p

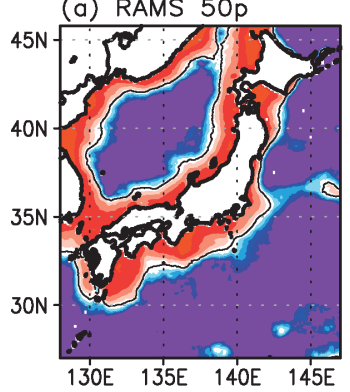

(b) NHM 50p

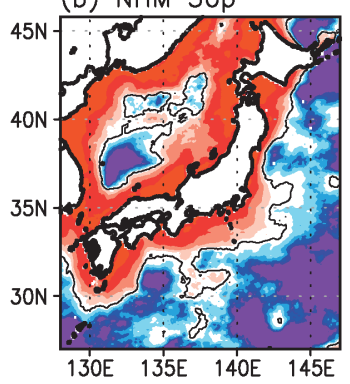

(c) WRF 50p

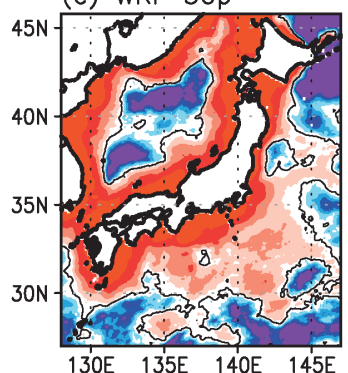

(d) Mean 50p

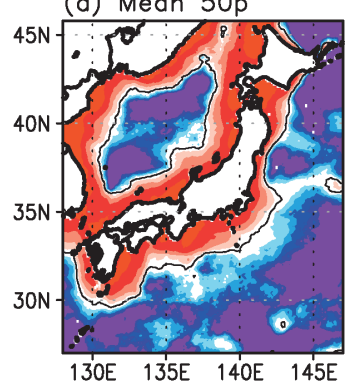

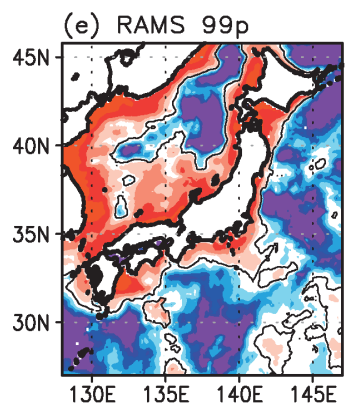
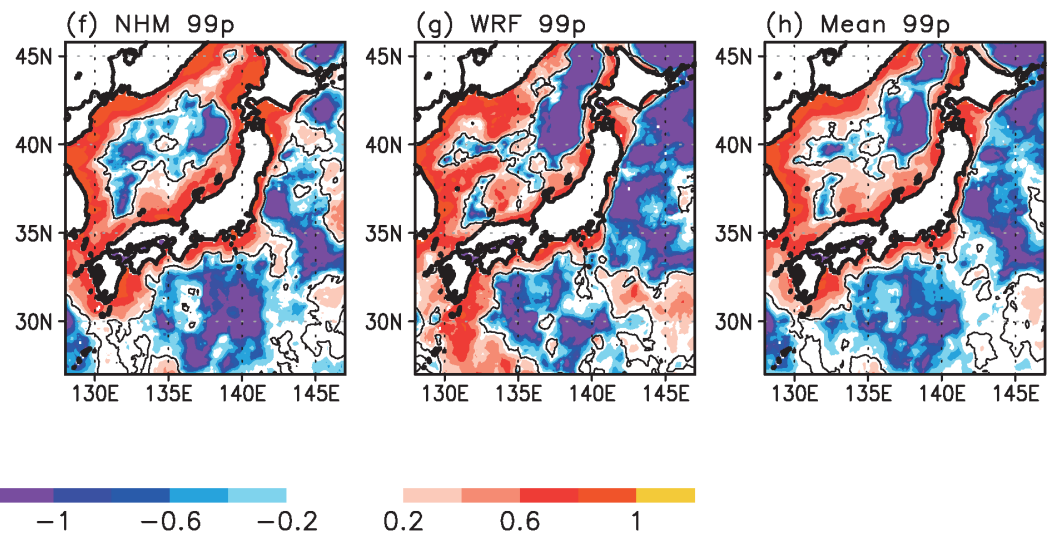

Fig. 4. Brier skill score of the monthly W50 (upper panels) and W99 (lower panels) for the RCMs during June-October of 2002-2004. Contour shows the zero-line. (d) and (h) show the mean BSS of all RCMs.

sufficiently resolved by the horizontal resolution of the wave model. Figure 3 shows the climatological JuneOctober mean of the monthly $50^{\text {th }}$ and $99^{\text {th }}$ percentiles of the observed significant wave height. There are higher $\mathrm{H}_{50}$ on the Pacific coast compared to the Japan Sea coast. The higher $\mathrm{H}_{50}$ on the Pacific coast results from a monsoonal southeasterly during boreal summer and fall. The monsoonal flow increases the wave height on the Pacific coast by the long-fetch, while the short-fetch on the Japan Sea coast does not increase the wave height. Figure $3 \mathrm{~b}$ shows that there are high $\mathrm{H}_{99}$ on the southern coast of Japan. This result is generally consistent with relatively high marine wind speed south of Japan (Fig. 2b). As Sasaki and Hibiya (2007) documented, the monthly $90^{\text {th }}$ percentile of significant wave height in the western North Pacific is strongly related with $\mathrm{TC}$ activity. The high $\mathrm{H}_{99}$ could be due to wind waves and swells induced by TCs.

\section{b. Observed sea surface temperature}

To validate sea surface temperature (SST) of the
JRA-25, we employ the Merged satellite and in situ data Global Daily Surface Temperatures (MGDSST). The MGDSST with $0.25^{\circ} \times 0.25^{\circ}$ grid resolution are analyzed on a near-real-time basis using SSTs from satellite infrared (AVHRR/NOAA) and microwave (AMSR-E/AQUA) sensors and the in-situ SSTs (Sakurai et al. 2005). We note that the horizontal resolution of the MGDSST is much higher than that of the JRA-25.

\section{Results}

\subsection{Capability of RCM approach in simulating marine wind around Japan}

We examine whether the dynamical downscaling approach brings added-value to simulate marine wind speed around Japan. To assess the capability of the dynamical downscaling approach, we utilize the Brier skill score (BSS) to test to what extent wind speed simulated by RCMs gives better reproduction of observed wind speed than wind speed simulated by the JRA-25. The BSS is defined, e.g. (von Storch and 
(a) RAMS 50p

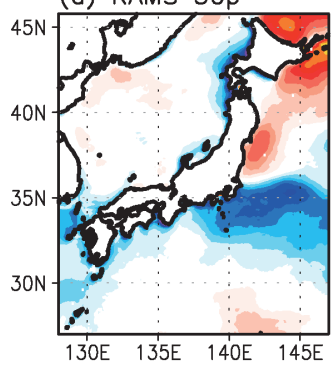

(b) NHM 50p

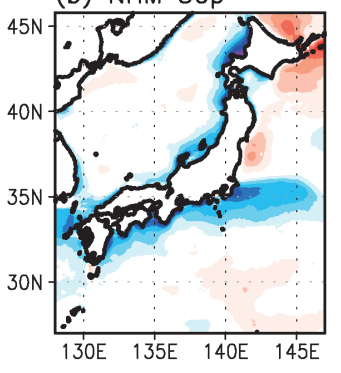

$-2$ (c) WRF 50p

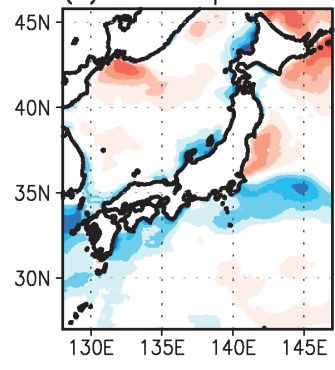

$0 \quad 1$ (d) Mean 50p

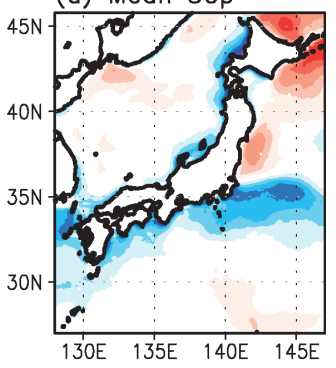

(h) Mean $99 \mathrm{p}$
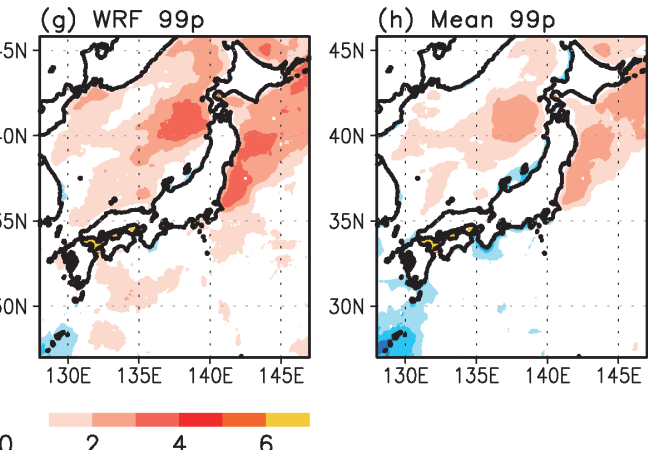
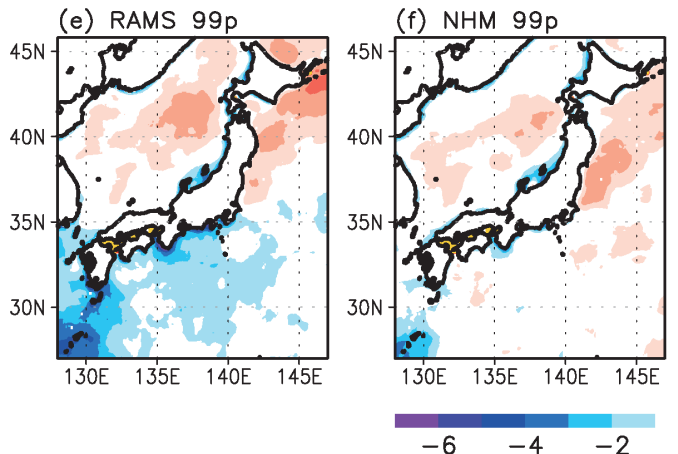

Fig. 5. The bias of $\mathrm{W}_{50}$ (upper) and $\mathrm{W}_{99}$ (lower) for the RCMs compared to the observed. Unit is $\mathrm{ms}^{-1}$.

Zwiers 1999), by

$$
\mathrm{BSS}=1-\sigma_{R C M}^{2} \sigma_{J R A}^{-2}
$$

where the $\sigma_{R C M}^{2}$ and $\sigma_{J R A}^{2}$ denote the error variances of marine wind speed simulated by a RCM and that of the JRA-25, respectively. The error variances are computed relative to wind speed of the BSW. By definition, the BSS varies between $-\infty$ to +1 . The negative values indicate better performance of the JRA-25, while positive values indicate better performance of the RCM. The zero value indicates that the performance of the RCM and that of the JRA-25 are comparable.

Figure 4 shows the BSS for marine wind speed around Japan. There are positive BSS along the coast, suggesting that the RCMs provide better performance than the JRA-25 in terms of simulating coastal wind speed as observed. In contrast, the RCM approach does not bring significant added-value to reproduce marine wind speed in the open ocean compared to the coastal wind speed. The better performance of the
JRA-25 in terms of simulating offshore wind speed results from good performance of the atmospheric general circulation model (AGCM) of the JRA-25 which assimilates various observed data as described in Subsection 2.1. In the next section, we discuss the performance of the RCM approach from the view point of the bias of wind speed.

\subsection{Bias for marine wind speed}

We evaluate the bias of marine wind speed for the JRA-25 and RCMs relative to the observed. Figures 2c and $d$ show the marine wind speed bias for the JRA- 25 . The JRA-25 considerably underestimates the coastal wind speed. The underestimation of the marine wind speed for the JRA-25 leads to an increase in the BSS, since the error variance of the JRA-25 ( $\sigma_{J R A}^{2}$ in Eq. 1) is increased. For the JRA-25, the bias of $\mathrm{W}_{99}$ is greater than that of $\mathrm{W}_{50}$ (Figs. 2c, d). Figure 5 shows the bias of marine wind speed for the RCMs relative to the observed. The coastal wind $\left(\mathrm{W}_{50}\right)$ biases for the RCMs are much smaller than the JRA-25, while there are still biases northeast of Japan and along the southern coast and Kuroshio Extension (Figs. 2c, 5a-d). The biases of 
(a) $\Delta$ SST (Jun-Aug)

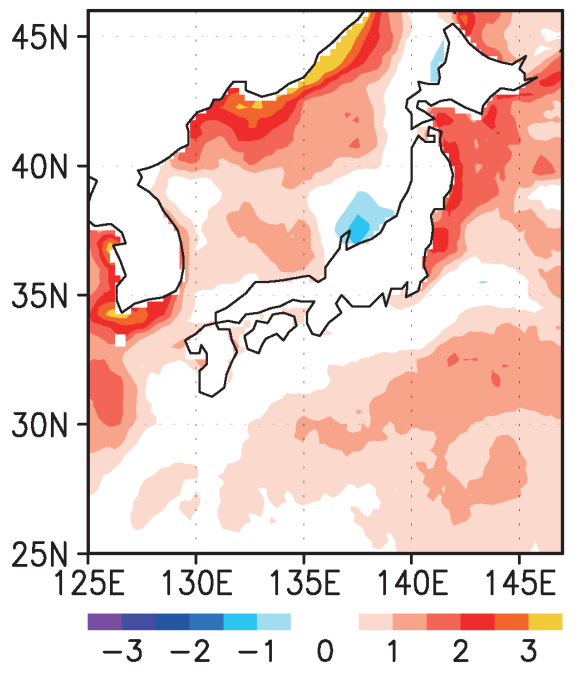

(c) $\triangle$ WINDSPEED (Jun-Aug)

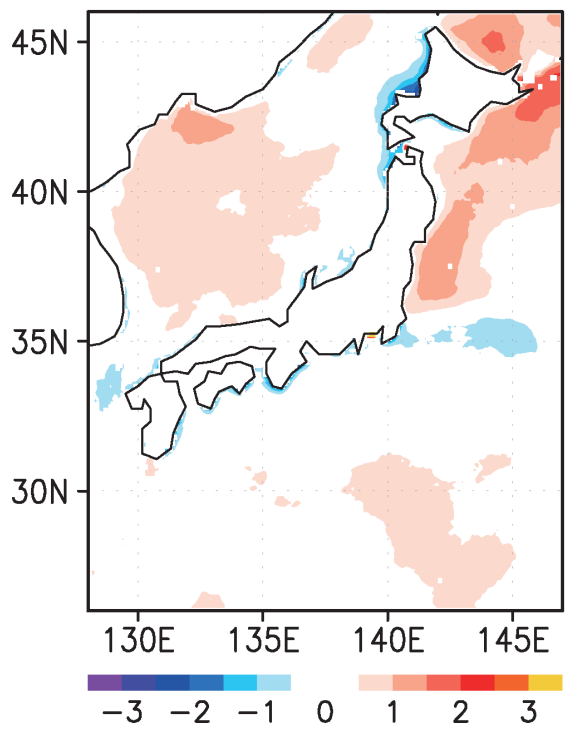

(b) $\Delta \mathrm{SST}(\mathrm{Sep}-\mathrm{Oct})$

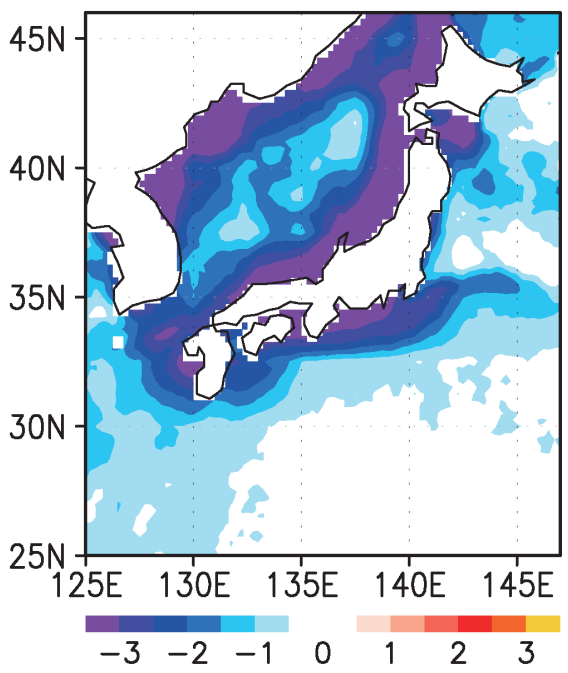

(d) $\triangle$ WINDSPEED (Sep-Oct)

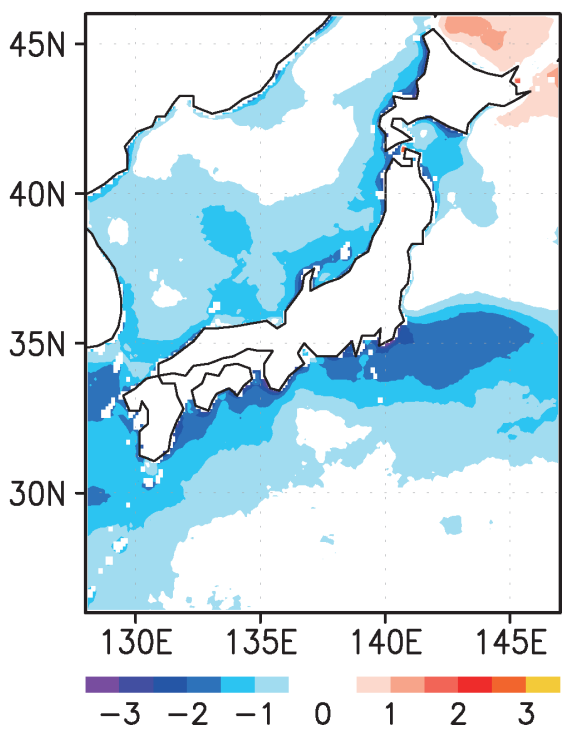

Fig. 6. (Upper) Difference in SST $\left({ }^{\circ} \mathrm{C}\right.$ ) between the JRA25 and MGDSST for (a) June-August and (b) September-October of 2002-2004. (Lower) As in the upper panels, but for the surface wind speed between the mean of three RCMs and BSW $\left(\mathrm{ms}^{-1}\right)$.

coastal $\mathrm{W}_{99}$ for the RCMs are also much smaller than the JRA-25, while there are positive biases around northern Japan and a negative one south of Japan (Figs. $2 \mathrm{~d}, 5 \mathrm{e}-\mathrm{h})$.

Although the RCMs simulate the coastal wind speed closer to the observed than the JRA-25, there are positive biases in $\mathrm{W}_{50}$ northeast of Japan and negative ones along the southern coast and Kuroshio Extension (Figs. 5a-d). The biases are similar in the spatial distribution among the RCMs, although the magnitudes of the biases are different (Figs. 5a-c). The negative bias in $\mathrm{W}_{50}$ over the Kuroshio Extension is also seen in the JRA-25 (Fig. 2c). This result indicates that the bias of $\mathrm{W}_{50}$ over the Kuroshio Extension possibly results from model-independent factors such as the lower boundary condition of the models. Interestingly, SST for the JRA-25 contains warm bias compared to the MGDSST northeast of Japan during 

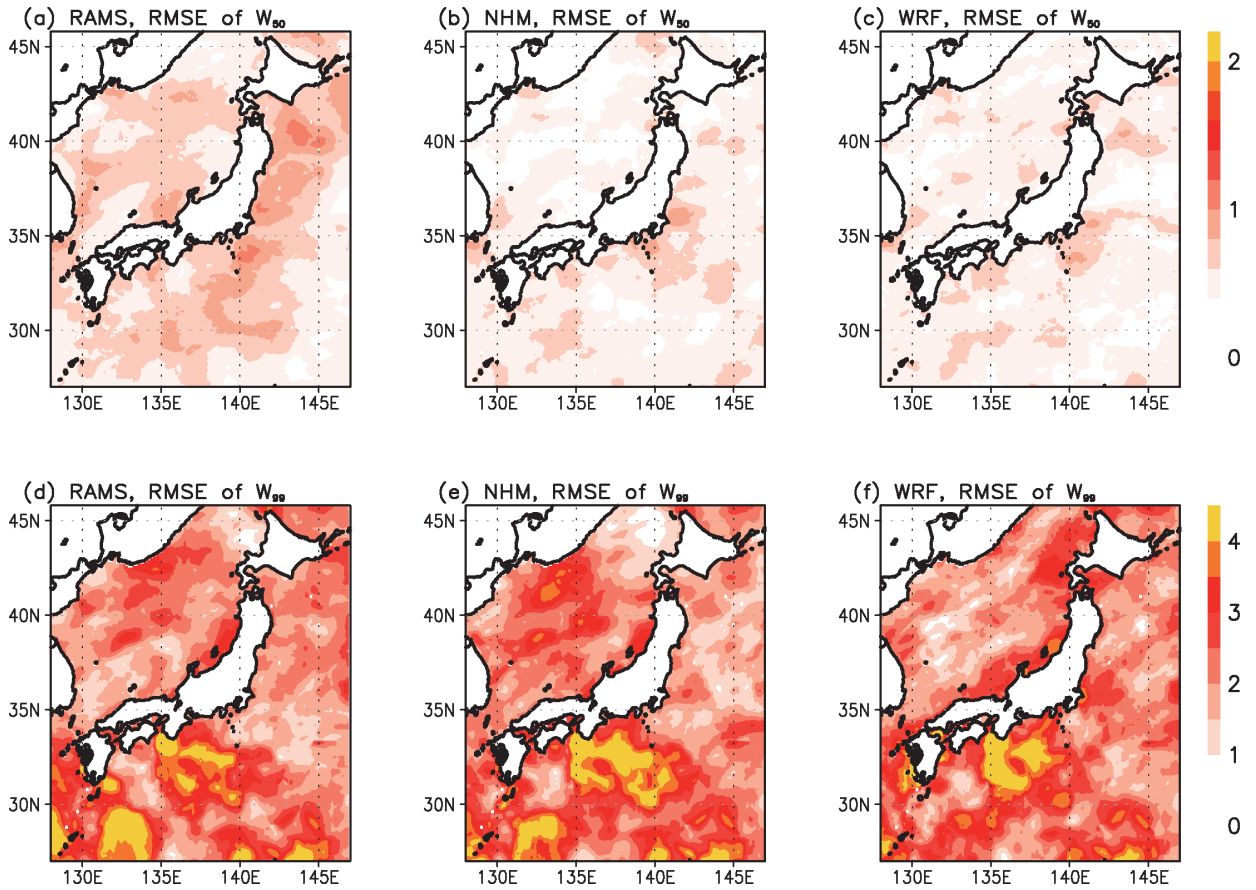

Fig. 7. As in Fig. 5, but for the root mean square error. The unit is $\mathrm{ms}^{-1}$.

boreal summer, while the former has a cold bias on the coastal area during boreal fall (Figs. 6a, b). The wind speed spatial pattern bias for the RCMs is consistent with that of SST (Fig. 6). This result agrees with the fact that surface wind speeds increase (decrease) in association with warm (cold) SST anomalies over the Kuroshio Extension (Nonaka and Xie 2003). We however note that there are possible biases of the BSW. The BSW are made of satellite-measured wind which is the equivalent neutral wind, inferred from observations of the ocean surface state assuming the neutral stratification of the surface atmosphere (Liu and Tang 1996; Liu et al. 2007). Over the Kuroshio Extension, SST is high and the surface atmosphere is more likely to be unstable, leading to overestimation of wind speed in the BSW. East of northeastern Japan, SST is low and satellite measurements are likely to underestimate wind speeds. Although the magnitude of the over/under-estimate may be less than $1 \mathrm{~ms}^{-1}$ (Liu and Tang 1996), part of the apparent bias of $\mathrm{W}_{50}$ of JRA-25 and RCMs may be due to biases in the BSW, so the actual model biases can be smaller than those shown in Figs. 2c and 5a-d.

The RCM approach also successfully reduces the bias of $\mathrm{W}_{99}$ on the Japanese coast, although there are positive (negative) biases north (south) of Japan (Figs.
$5 \mathrm{e}-\mathrm{h})$. The negative bias in wind speed south of Japan (particularly for the RAMS) would be induced by the insufficient intensity of modeled TCs, even though the area is close to the lateral boundary of the RCMs.

\subsection{Month-to-month variability of marine wind speed of $R C M s$}

We compare the root mean square error (RMSE) of marine wind speed for the RCMs to evaluate the reproducibility of the month-to-month variability. To eliminate the effect of the bias, the monthly anomalies are utilized. Figure 7 shows the RMSE of the marine wind speed for the RCMs. The RMSEs of $\mathrm{W}_{50}$ for the RCMs are up to $1 \mathrm{~ms}^{-1}$, which is considerably larger than those for the JRA-25 (Fig. 2e), suggesting that the RCMs have a problem in reproducing the monthto-month variability of $\mathrm{W}_{50}$. On the other hand, the RMSE of $\mathrm{W}_{99}$ for the RCMs is slightly larger than that for the JRA-25 (Figs. 2f, 7d-f). In particular, all RCMs simulate large RMSEs south of Japan (Figs. 7d-f). If looking carefully, there are large RMSEs of $\mathrm{W}_{99}$ within the region, $27^{\circ} \mathrm{N}-30^{\circ} \mathrm{N}, 130^{\circ} \mathrm{E}-135^{\circ} \mathrm{E}$ for RAMS and NHM, while the RMSEs for WRF is relatively small (Figs. 7d-f). On the other hand, all RCMs simulate large RMSEs of $\mathrm{W}_{99}$ within the region of $30^{\circ} \mathrm{N}-35^{\circ} \mathrm{N}$, $135^{\circ} \mathrm{E}-140^{\circ} \mathrm{E}$ (Figs. $7 \mathrm{~d}-\mathrm{f}$ ). These results indicate that 
(a) RAMS 50p

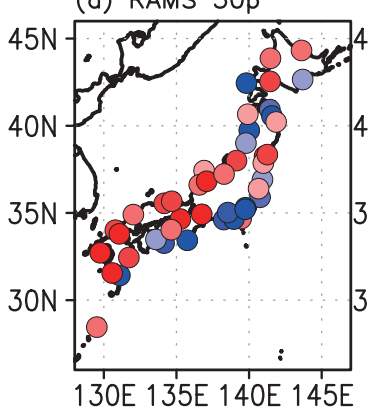

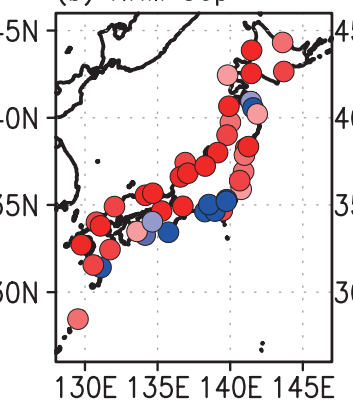

(c) WRF 50p

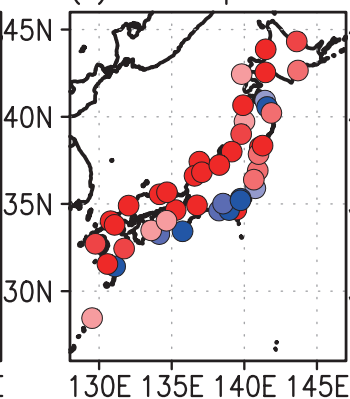

(d) Mean 50p

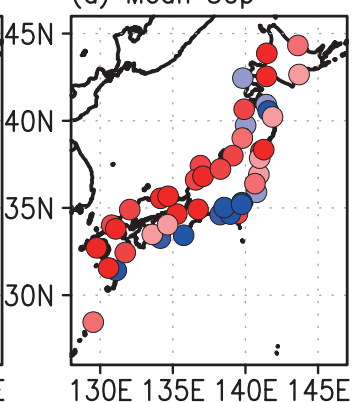

(e) RAMS $99 \mathrm{p}$

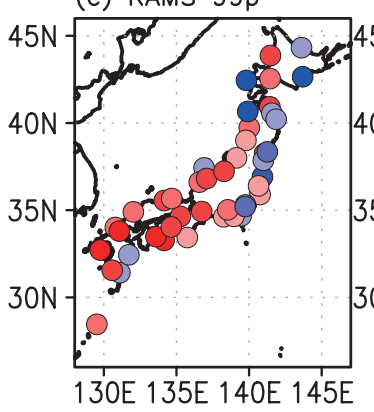

(f) NHM $99 \mathrm{p}$

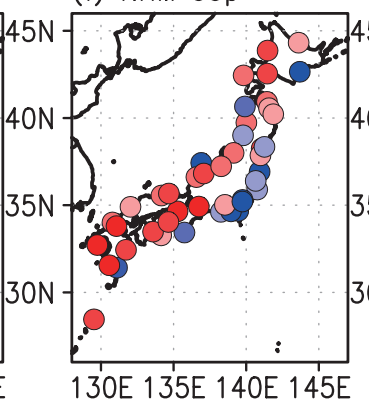

(g) WRF 99p
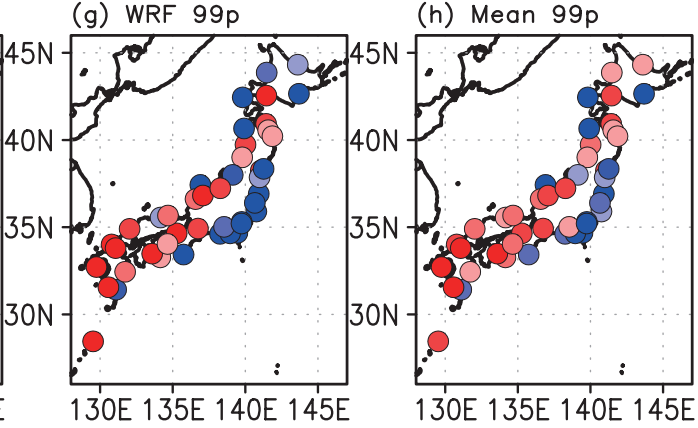

0.7

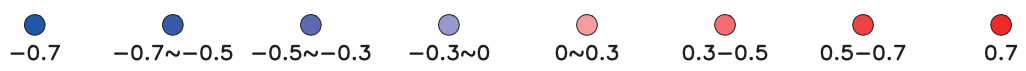

Fig. 8. The Brier Skill Score of the monthly $50^{\text {th }}$ (upper panels) and $99^{\text {th }}$ (lower panels) percentile of significant wave height simulated by three RCM winds.

there are uncertainties in the month-to-month variability of high wind speed attributable to the difference in the RCMs. We note that the area of the high uncertainty identified here is not robust, since only three RCMs are employed for this study. Additional ensemble member would be necessary to reduce the uncertainty of wind speed.

\subsection{Response of surface wave model to marine winds of RCMs}

To verify the capability of the marine winds simulated by the RCMs in terms of reproducing the temporal variation of significant wave height, we evaluate the BSS of $\mathrm{H}_{50}$ and $\mathrm{H}_{99}$. The BSS of $\mathrm{H}_{50}$ and $\mathrm{H}_{99}$ are calculated from Eq. (1). The error variance of significant wave height simulated by the RCM winds $\left(\sigma_{R C M}^{2}\right)$ and that simulated by the JRA-25 winds $\left(\sigma_{J R A}^{2}\right)$ are computed relative to observed significant wave height. Figure 8 shows the BSS of $\mathrm{H}_{50}$ and $\mathrm{H}_{99}$, suggesting that the RCM winds are more effective than the JRA- 25 winds in reproducing $\mathrm{H}_{50}$ on the Japan Sea coast and $\mathrm{H}_{99}$ around the western Japan. In particular, high BSS of $\mathrm{H}_{99}$ is seen in the far-southwest of Japan $\left(30^{\circ} \mathrm{N}-35^{\circ} \mathrm{N}, 129^{\circ} \mathrm{E}-131^{\circ} \mathrm{E}\right)$ (Figs. 8e-h). In contrast, the RCM winds have relatively less capability in reproducing significant wave height on the southern coast of Japan (Fig 8).

We focus on changes in the bias of modeled significant wave height, since the RCM approach successfully reduces the strong negative bias of coastal wind speed for the JRA-25 (Subsection 3.2). Figure 9 shows the bias of significant wave heights simulated by the JRA- 25 winds. The marine winds of the JRA-25 underestimate significant wave heights along the Japan Sea coast. This result is consistent with the low coastal wind speed of the JRA-25 (Figs. 2c, d). Whereas, $\mathrm{H}_{99}$ on the Pacific coast is not negatively biased (Fig. 9b), even though the coastal wind speed of the JRA-25 is much lower than the observed (Figs. 2c, d). We also find that there is not much negative bias of $\mathrm{H}_{50}$ on the Pacific coast (Fig. 9a) in spite of the low coastal wind of the JRA-25 (Fig. 2c). The fact that wave simulation is 


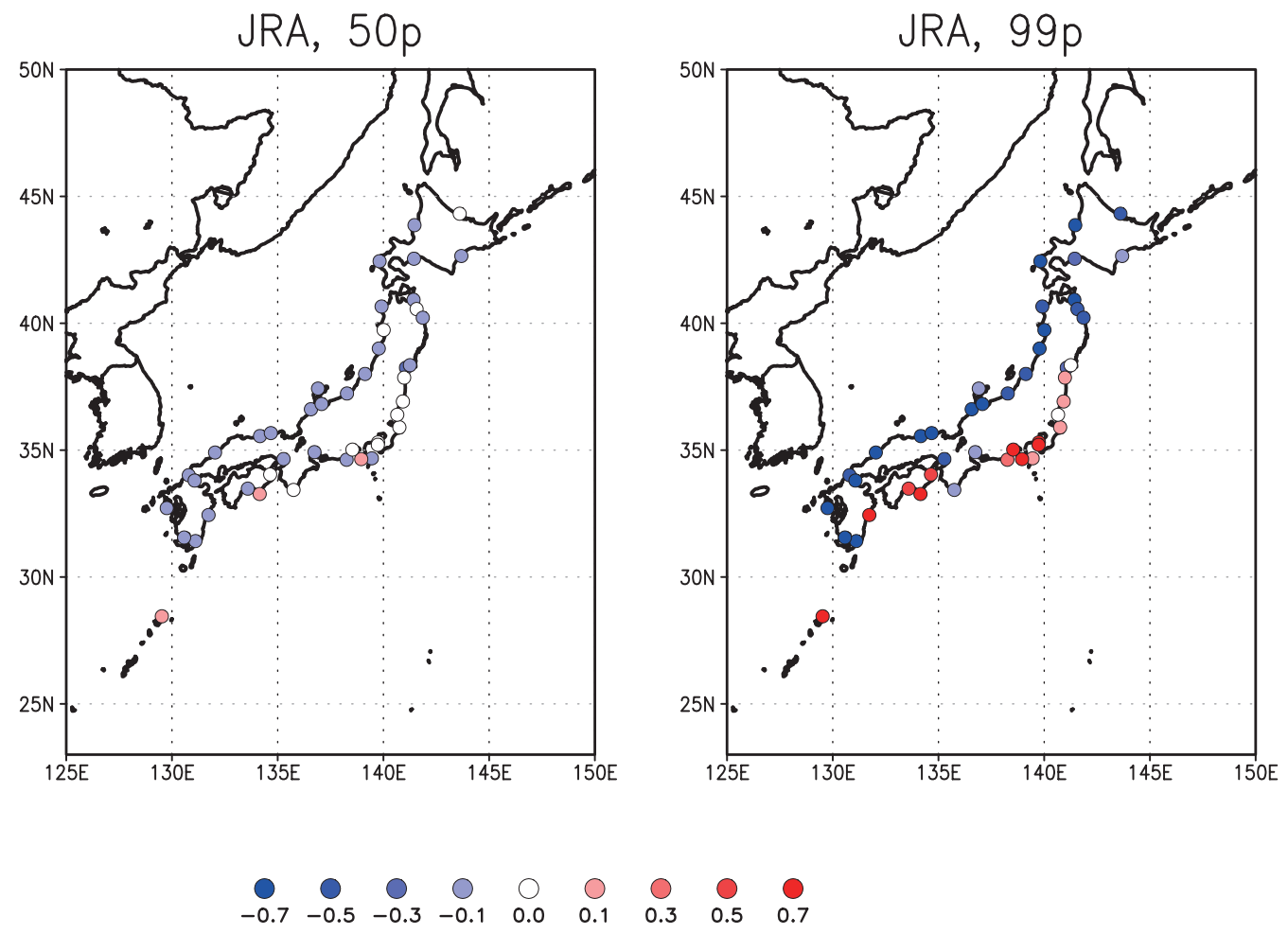

Fig. 9. The bias of (a) $\mathrm{H}_{50}$ and (b) $\mathrm{H}_{99}$ simulated by the JRA-25 marine winds relative to the observed. Unit is m.

successful in spite of the erroneously low coastal wind speed suggests a possible problem with the wave model. Hanson et al. (2008) found that the WaveWATCH III overestimates swell heights in the Pacific. We speculate that the wave model overestimates swell heights caused by monsoonal southeasterly and TCs in the western North Pacific during boreal summer and fall. The overestimates of $\mathrm{H}_{99}$ along the southern coast simulated by the RCM winds (lower panels of Fig. 10) also could be caused by the overestimates in swell heights in the western North Pacific. On the other hand, wave heights along the Japan Sea coast are relatively well simulated as observed (upper panels of Fig. 10). The well simulated wave heights along the Japan Sea coast could be due to short-fetch length and time.

\section{Summary and Discussion}

We have assessed using three RCMs, the capability of dynamical downscaling approach in simulating coastal winds and waves around Japan during TC season of 2002-2004. It has been found that the RCM approach provides better performance than the JRA-25 in terms of simulating coastal wind speed around Japan. We have found that the biased coastal marine wind speed of the JRA-25 is considerably improved by utilizing the RCMs. On the other hand, the RMSE of the coastal wind speed for the JRA-25 is not drastically changed by the RCM approach. These results suggest that the better performance of the RCM approach results from a reduction of the bias rather than that of the RMSE. The RCMs however still simulate biased marine wind speed northeast of Japan, and along the southern coast and Kuroshio Extension. We note that SST for the RCMs is spatially interpolated from the JRA-25 SST. It has been found that the spatial pattern of the bias of the RCM wind speed agrees well with that of SST for the JRA-25, leading to the suggestion that the biased RCM wind speed is caused by the erroneous SST associated with the insufficient horizontal resolution of the JRA25. This result indicates that high-resolution SSTs are indispensable for the RCM simulation to reproduce coastal wind speed around Japan as observed.

The marine winds of the RCMs have been found to be more effective than the JRA-25 winds in reproducing significant wave height on the Japan Sea coast. The better performance of the RCMs in terms of simulating significant wave height results from the successful simulation of coastal wind speed in the RCMs. In this 
(a) RAMS 50p

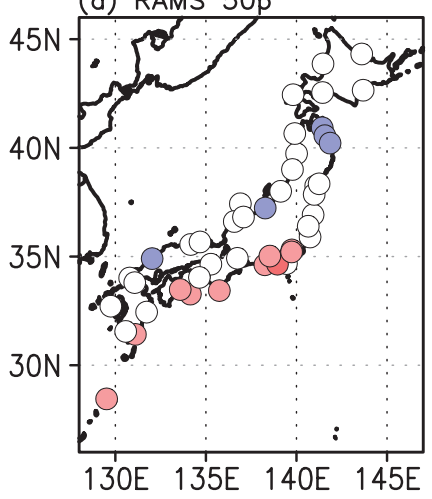

(d) RAMS 99p

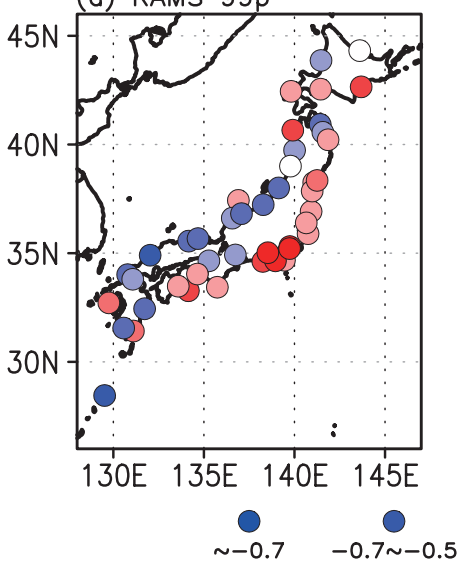

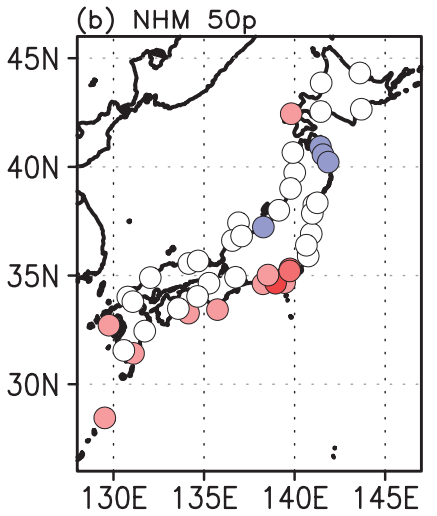

(e) NHM $99 \mathrm{p}$

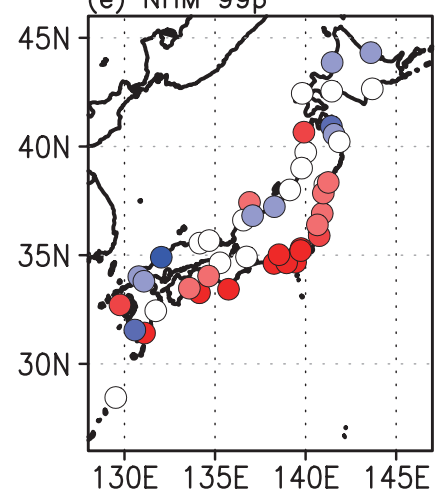

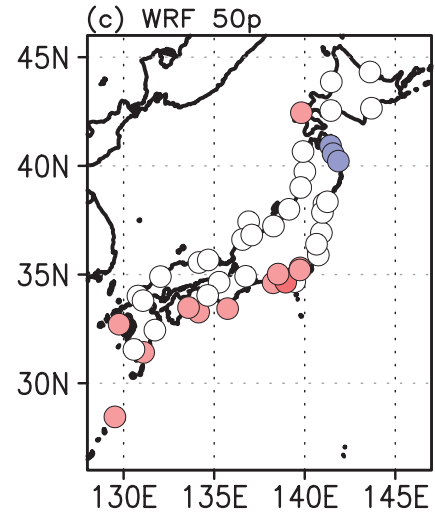

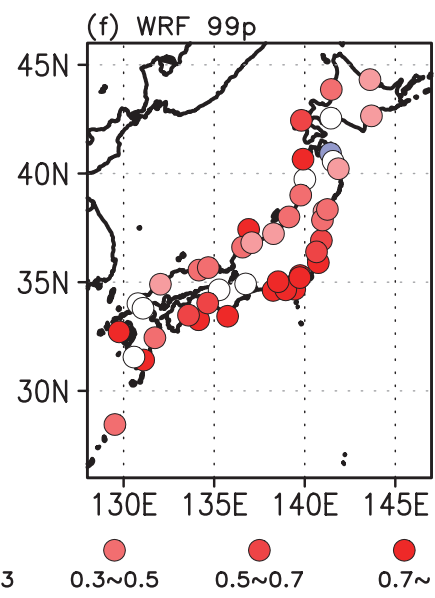

Fig. 10. The bias of $\mathrm{H}_{50}$ (upper) and $\mathrm{H}_{99}$ (lower) for RCM winds relative to the observed. Unit is $\mathrm{m}$.

study, simulation of significant wave height along the Pacific coast of Japan is unsuccessful. For instance, the RCMs simulate excessively high wave heights off the Pacific coast of Japan, despite wind speeds being low (Fig. 10). A possible reason is the overestimation of swell heights in the wave model (Hanson et al. 2008).

The underestimation of coastal wind speed of the JRA-25 can be a result either from the underestimation of coastal marine wind itself of the JRA-25 or from the misrepresentation of the surface condition due to the coarse resolution of the land-sea mask of the JRA-25, since the coastal wind speed over the coarse grid point includes surface wind speed over the land. To examine the underestimates of the coastal wind speed of the JRA-25, the surface wind speed over land is compared between the RCMs and JRA-25. To compare the surface wind speeds, wind data from the RCMs are averaged to match the grid of the JRA-25. Figure 11 shows a difference in surface wind speed between the mean of all RCMs and JRA-25. There is an increased surface wind speed over land as well as the coast induced by the dynamical downscaling. Although the validity of surface wind speed over land simulated by the RCMs is still unclear, this result indicates that coastal wind speed of the JRA-25 is underestimated by including the low surface wind speed over land. Thus, the impact of surface winds over land on coastal winds around Japan remains a topic for future study to improve coastal wind and wave simulation.

\section{Acknowledgments}

We thank anonymous reviewers for their valuable comments that helped to improve the manuscript. We also thank the following people who supplied data: the NHM wind data were provided by Drs. N. N. Ishizaki (JAMSTEC) and I. Takayabu (Meteorological Research Institute). The WRF wind data were provided by Drs. S. A. Adachi and F. Kimura (JAMSTEC). The 


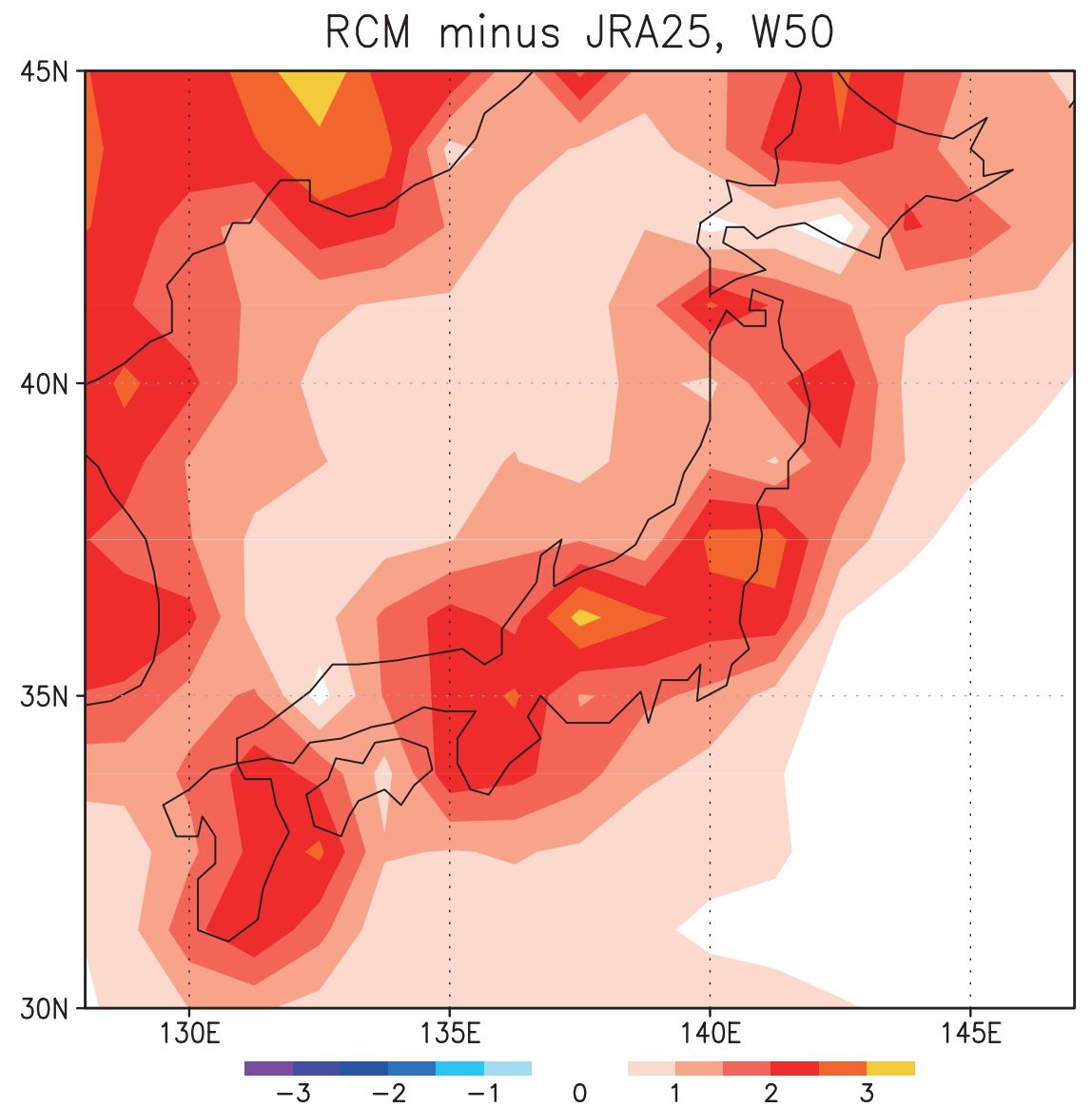

Fig. 11. Difference in $\mathrm{W}_{50}$ between the mean of three RCMs and the JRA-25. Unit is $\mathrm{ms}^{-1}$.

NOWPHAS wave data was provided by Port and Airport Research Institute. This work was supported by the Global Environment Research Fund (S-5-3) of the Ministry of the Environment, Japan and supported in part by the Research Program on Climate Change Adaptation (RECCA program).

\section{References}

Dairaku, K., S. Iizuka, W. Sasaki, A. Beltran, and R. A. Pielke (2008), Assessment of dynamical downscaling in Japan using an atmospherebiosphere-river coupling regional climate model, Eos, Trans. Amer. Geophys Union, 89, Fall Meet. Suppl., Abstract GC53A-0687.

Hanson, J. L., B. A. Tracy, H. L. Tolman, and R. D. Scott, Pacific hindcast performance of three numerical wave models, J. Atmos. Ocenic Technol., 26, pp. 1614-1633.

Liston, G. E., and R. A. Pielke, 2000: A Climate Version of the Regional Atmospheric Modeling System, Theor. Appl. Climatol., 66, pp. 29-47.
Liu, W. T., and W. Tang 1996: Equivalent neutral wind. JPL Publication 96-17, Jet Propulsion Laboratory, California Institute of Technology, Pasadena, CA, 16 pp.

Liu, W. T., X. Xie, and P. P. Niiler, 2007: Ocean-atmosphere interaction over Agulhas extension meanders. $J$. Climate, 20, 5784-5797.

Narita, M., and S. Ohmori, 2007, Improving precipitation forecasts by the operational nonhydrostatic mesoscale model with the Kain-Fritsch convective parameterization and cloud microphysics, paper presented at 12th Conference on Mesoscale Processes, Am. Meteorol. Soc., Waterville Valley, N. H.

Ohmori, S., and Y. Yamada, 2004, Implementation of the Kain-Fritsch convective parameterization scheme in the JMA's non-hydrostatic model, CAS/JSC WGNE Res. Activ. Atmos. Oceanic Modell., 34, 425-426.

Onogi, K., and co-authors, 2007, The JRA-25 Reanalysis, $J$. Meteor. Soc. Japan, 85, No.3, pp.369-432.

Parry, M. L., O. F. Canziani, J. P. Palutikof, P. J. van der 
Linden, and C. E. Hanson, Eds., 2007: Contribution of Working Group II to the Fourth Assessment Report of the Intergovernmental Panel on Climate Change, Cambridge University Press, Cambridge, UK, 976 pp.

Rummukainen, M., 2010: State-of-the-art with regional climate models, Wiley Interdisciplinary Reviews: Climate Change, 1, pp.82-96, doi:10.1002/wcc.8.

Saito, K., J. Ishida, K. Aranami, T. Hara, T. Segawa, M. Narita, and Y. Honda, 2007: Nonhydrostatic Atmospheric Models and Operational Development at JMA, J. Meteor. Soc. Japan, 85B, pp. 271-304.

Sasaki, W., and T. Hibiya, 2007: Interannual variability and predictability of summertime significant wave heights in the western North Pacific, J. Oceanogr., 63, pp.
203-213.

Skamarock, W. C., J. B. Klemp, J. Dudhia, D. O. Gill, D. M. Barker, W. Wang, and J. G. Powers, 2007: A Description of the Advanced Research WRF Version 2, NCAR TECHNICAL NOTE.

Tolman, H., 2002: User manual and system documentation of WAVEWATCH-III version 2.22, NOAA/NWS/NCEP/ MMAB Technical Note, 222, 133 pp.

von Storch, H., and Zwiers, F. 1999: Statistical Analysis in Climate Research, Cambridge University Press.

Zhang, H.-M., J. J. Bates, and R. W. Reynolds, 2006: "Assessment of composite global sampling: Sea surface wind speed", Geophys. Res. Lett., 33, L17714, doi:10.1029/2006GL027086. 